\title{
Recent experimental enhancement techniques applied in the receiver part of the parabolic trough collector - A review
}

\section{International Review of Applied Sciences and Engineering}

$11(2020) 3,209-219$

DOI:

$10.1556 / 1848.2020 .00055$

(c) 2020 The Author(s)

\section{O. AL-ORAN* (1) and F. LEZSOVITS}

Department of Energy Engineering, Faculty of Mechanical Engineering, Budapest University of Technology and Economics, Muegyetem rkp. 3., 1111 Budapest, Hungary

Received: September 23, 2019 • Accepted: February 2, 2020

Published online: October 12, 2020

\section{REVIEW PAPER}

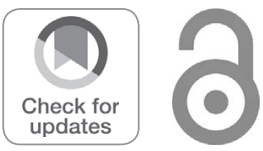

*Corresponding author.

E-mail: aloran@energia.bme.hu

\begin{abstract}
Recently, the thermal performance of the parabolic trough collector (PTC), augmented to be more applicable and efficient, received intensive research. These studies aimed to improve heat transfer in the receiver part, in order to decrease the heat loss, and enhance the heat transfer to the thermal fluid. Many previous review papers focused on the numerical sides rather than the experimental side. Several research papers recommended doing more research in the experimental field; in order to decrease the gap between the numerical and experimental results, as well as increase the confidence level of what has been done in the theoretical field researches. Regarding the recommendations of the recent papers to decrease the gap between numerical and experimental aspects, this review paper focused on the recent experimental research related to thermal enhancement performance in the receiver part of the parabolic solar collector. In this research, different categories of the enhancement methods are discussed in detail through this review, namely nanofluids, surface modifications, and inserts models or the two categories combined together. We discussed these categories for different parabolic troughs considering only the recent experimental research between the period from 2014 up to 2019. Some parameters were discussed, such as the main dimensions of the examined receiver and parabolic collector. Moreover, types of nanoparticle specifications and preparation methods with different base fluids were highlighted. In addition, we discussed different aspects of using inserts models and inlet and outlet surface modification methods. Finally, the main thermal efficiency and thermal performance enhancement results for each work were presented.
\end{abstract}

\section{KEYWORDS}

parabolic trough collector, experimental, thermal performance enhancement, nanofluid, geometrical modification, inserts flow

\section{INTRODUCTION}

Many issues play a key role in strengthening the need to use renewable energy to achieve the desired sustainable development. Those issues can be summarized: high deteriorating of fossil fuel level concurrent with growing demand, a swift increase of electricity cost, and environmental issues (i.e., acid rain, greenhouse issues, and ozone depletion) [1,2]. Alternative clean energy authorities such as solar, wind, geothermal, and biomass have a significant effect on minimizing the impact of pollution and the shortage of fossil fuel [3, 4]. Many reasons support the usage of solar energy as a source of energy more than other renewable sources such as its availability, its ability to be transported effectively to produce power, and its ability to synchronize with other applications [5]. Plenty of scientific research has been conducted in using solar energy concentrating on the: ability to produce energy from solar radiation intensity and to get the benefit both of its economic implements and the consequences of solar energy synchronizing with other direct and indirect applications such as heating, refrigeration, drying, and chemical industrial processes [6-8]. PTC is one of the oldest concentrated solar power (CSP) types used widely in recent years. Where the first appearance of this type 
referred was in 1870; when engineer Johan Ericsson designed a parabolic trough of $3.25 \mathrm{~m}^{2}$ to produce $373 \mathrm{~W}$, and this parabolic trough was called a direct steam generator [9]. The ability to supply high temperature parallel with the high performance of thermal efficiency and the economic cost, these principles support the use of PTC more than any CSP applications [10,11]. Besides this importance, recently, there are many studies concerned about the PTC from different aspects such as: modification in design geometry, optical efficiency, heat transfer enhancement in the receiver part, and different synchronized applications. Each of these aspects aimed to strengthen thermal efficiency to produce high power energy as explained and discussed in the various review papers. Hafez et al. [12] in their review covered the main results of the theoretical and experimental aspects of the PTC between the period 1981-2016. Abdulhamed et al. [13] discussed several types of researches related to the thermal analysis and the effect of the improved methods in a PTC, in addition to the effect of using PTC in different applications such as heating, desalination, power plants, and industrial fields. The enhancement of thermal performance in the receiver part has taken a high intensity in many types of researches and summarized in different review papers. Akbarzadeh and Valipour [14] explained the design parameters of the PTC, but they focused on the enhancement heat transfer using different passive techniques, especially nanofluid methods. Khanafer and Vafai [15] presented the effects of inserting nanofluid as a thermal heating fluid in

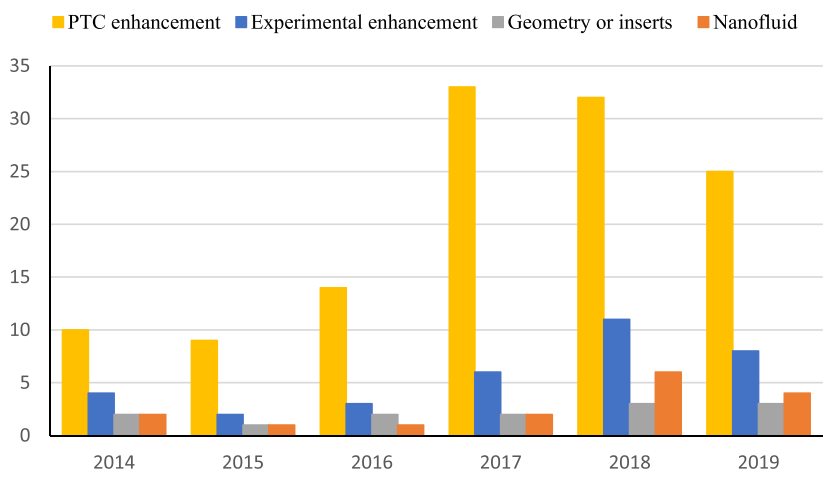

Fig. 1. Articles number distribution for the enhancement performance of PTC for the period 2014-2019

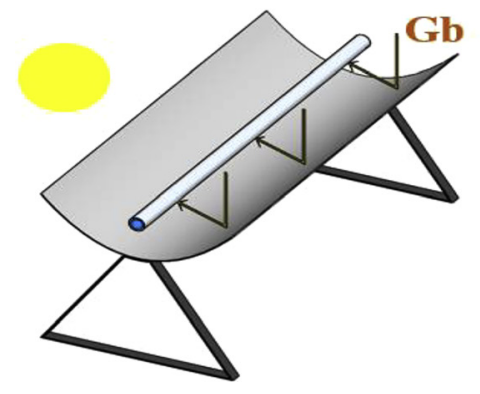

different applications and discussed recent thermal physical correlations used to define different thermal properties.

Depending on the literature, several review papers represented the researches that related to the enhancement of heat transfer, geometry, optical efficiency, thermal energy, and exergy efficiency results and modeling of the PTC. There is no review specialized in the experimental work of enhancing technique in the receiver of PTC, despite recommendations to increase research related to the experimental work to decrease the shortage between theoretical simulation aspect and experimental aspect. Therefore, this paper aims to explain the experimental thermal performance enhancement in the receiver part of the PTC thoroughly from recent years in various categories, as mentioned in the following points:

- Mono and hybrid nanofluid enhancement.

- Modification geometry and inserts flow enhancement.

- Coupled previous categories together.

The recent years show an increase in the number of studies related to the augmentation techniques effect in the receiver part, which leads to enhancing the thermal performance of the whole system. Fig. 1 shows the article numbers that we found in the Scopus database on 10 September 19 using the words "parabolic trough collector," and "enhancement," published between the years 2014-2019. Besides classifying these articles upon the experimental enhancement methods that were used, Fig. 1 shows the high variation between the total article numbers and number of the experimental articles, which variation can be attributed to the numerical studies and review papers in this field. Moreover, this figure presents the variation in the article numbers by using nanofluids and geometry or inserts categories, that aimed to enhance the performance of the PTC experimentally.

\subsection{Parabolic trough components}

Parabolic trough collector (PTC) consists of the mirrors arranged on parabola shape to convert and concentrate direct beam irradiance intensity $\left(\mathrm{G}_{\mathrm{b}}\right)$ on the heating collecting element to enhance the temperature of the thermal fluid (TF) as illustrated in Fig. 2. Whereas the receiver part takes a high interest, so it is covered with a glass envelope, coated with high absorptivity material, and evacuated space

Fig. 2. Parabolic trough and receiver side section schematics

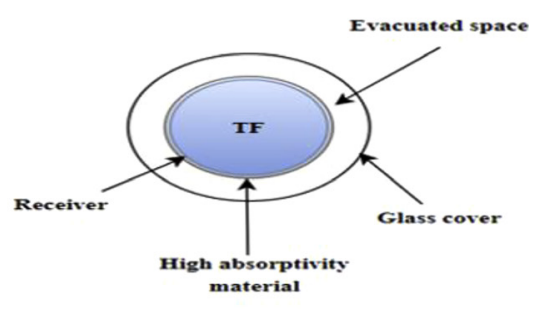




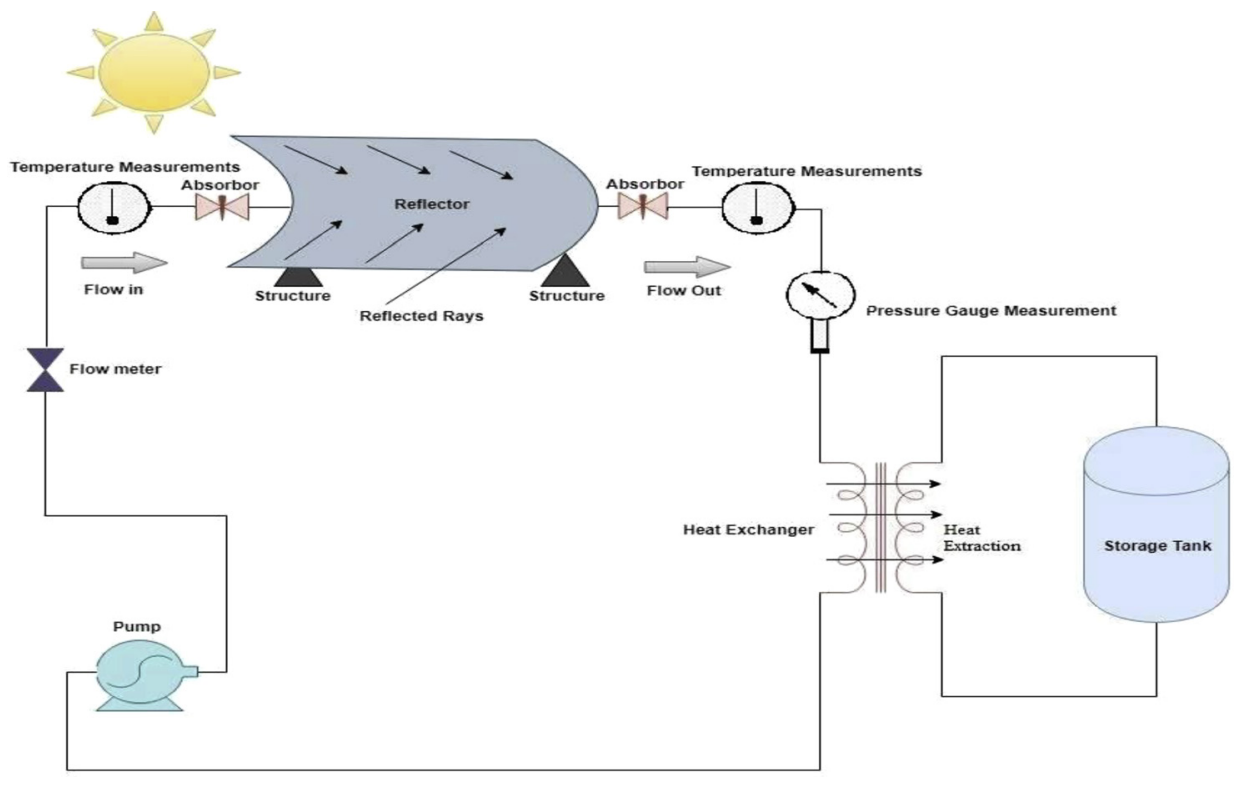

Fig. 3. Conceptual schematic cycle

to minimize heat losses and to raise heat transfer to TF flow inside the receiver, as shown in Fig. 2.

Many scientific experimental works through this review comprise a cycle having several components namely: PTC, pump, storage tank, pipes, and measurement items to measure solar radiation, temperature, pressure, and flow rate at the inlet and the outlet of the PTC, whereas some studies also have a heat exchanger. Fig. 3 comprises a conceptual schematic of the main components.

\subsection{Experimental methodology procedures}

The method of the experimental work for the various articles is based mainly on the same procedures. In the following section, the main equations and procedures sequence to derive thermal efficiency are presented.

The thermal efficiency of the PTC is defined as the ratio between useful energy and sensible energy, as presented in Eq. (1) [16].

$$
\eta_{t h}=\frac{Q_{u}}{Q_{s}}
$$

The useful energy gain transferred to the fluid is defined as represented in Eqs. (2) and (3) [16].

$$
Q_{u}=\dot{m} \cdot C_{p . f l u i d} \cdot\left(T_{f l u i d, o u t}-T_{\text {fluid,in }}\right)
$$

where $C_{p . f l u i d}$ is specific heat capacity of the fluid $[\mathrm{J} / \mathrm{kg} \mathrm{K}], \dot{m}$ is the mass flow rate of the fluid $[\mathrm{kg} / \mathrm{s}]$, finally temperature difference between outlet and inlet temperature $[\mathrm{K}]$

$$
Q_{s}=A_{a p} \cdot G_{b}
$$

where the sensible heat is predicted by the multiplied aperture area of the PTC $A_{a p}$, and direct beam irradiance intensity reaches the reflected area $G_{b}$.

Eq. (4) is used to represent heat losses energy $Q_{\text {loss }}$ of the collector, where the derived thermal loss coefficient $U_{l}$ is multiplied by the outer receiver area $A_{r, o}$, and the temperature difference produced between the receiver and ambient $T_{r}, T_{a m b}$.

$$
Q_{\text {loss }}=U_{l} \cdot A_{r, o} \cdot\left(T_{r}-T_{a m b}\right)
$$

The methodology of the experimental works is based on the collected data of the difference between inlet and outlet temperatures, mass flowrate, variable radiation intensity, and the fluid properties specifications, while the instantaneous efficiency and the overall efficiency can be calculated accordingly to the obtained measurement data. Usually, the thermal efficiency of the PTC is described using a graph which shows the thermal efficiency variation in the $y$-axis versus the heat loss parameter $\left(T_{\text {in }}-T_{a m b} / G_{b}\right)$ in the $x$-axis, or thermal efficiency variation in the $y$-axis versus the solar time in the $x$-axis $[11,17]$.

\subsection{Design parameter}

Through this scientific review paper, the main parameter of the parabolic trough and heating collecting element (receiver) used in various researches is summarized as shown in

Table 1 shows that the experimental works do not take a high interest according to the few numbers of the mentioned articles. The scientific studies in India focused on enhancing the thermal performance of the PTC and manufactured their constructions more than others. Various experimental researches were built based on using the manufacturing PTC not using a commercial one.

\section{THERMAL PERFORMANCE ENHANCEMENT}

Economically enhancing thermal performance in the receiver part plays a vital role in making PTC more efficient 
Table 1. Main specifications of the PTC and receiver parts of the experimental articles

\begin{tabular}{|c|c|c|c|c|c|}
\hline Author and Ref. & Location & $\begin{array}{l}\text { Length }(\mathrm{L}) \text { and } \\
\text { width }(\mathrm{W}) \mathrm{m}\end{array}$ & $\begin{array}{l}\text { Absorber diameter } \\
D_{o}, D_{i n}, \mathrm{~mm}\end{array}$ & Rim angle & $\begin{array}{c}\text { Concentrated } \\
\text { ratio }\end{array}$ \\
\hline Rehan et al. [17] & Pakistan & $2.05,1.04$ & 22,20 & 108 & 11 \\
\hline De los Rios et al. [18] & Mexican & $3.06,1.21$ & NA & NA & NA \\
\hline Subramani et al. $[19,20]$ & India & $2,0.8$ & 16,13 & 80 & 15.6 \\
\hline Alsaady et al. [21] & Simulator LAB & $0.5,0.25$ & $15,-$ & NA & NA \\
\hline Kasaeian et al. [22] & Iran & $2,0.7$ & 28,26 & 90 & - \\
\hline Chaudhari [23] & India & - & - & - & - \\
\hline Ajay and Kundan [24] & India & $1.2,0.915$ & 28,27 & 90 & 9.66 \\
\hline Tagle-Salazar et al. [25] & Mexican & $3,1.1$ & - & - & - \\
\hline Potenza et al. [26] & Italy & $1.6,2.5$ & 43,40 & - & - \\
\hline Menbari et al. [27] & DAPTC (Iran) & $1,0.85$ & $20,-$ & - & - \\
\hline Kasaeian et al. [28] & DAPTC Iran & $2,0.7$ & 26,24 & 90 & - \\
\hline Jamal-Abed et al. [29] & Iran & $1.28,1$ & $28,-$ & 90 & - \\
\hline Jafar and Sivaraman [30] & India & 2,1 & $12,12.5$ & - & 25.46 \\
\hline Bhakta et al. [31] & India (Eco-SCTS2.1) & $1.22,0.834$ & 23,25 & 67.24 & 20.598 \\
\hline Nemś and Kasperski [32] & Poland Prototype & $0.5,1.2$ & $50,-$ & - & 19.1 \\
\hline Reddy et al. [33] & India & $3,2.5$ & 60,54 & 65 & 26 \\
\hline Waghole et al. [34] & Simulator LAB & $1.5,-$ & 22,20 & - & - \\
\hline
\end{tabular}

to use. This enhancement aims to improve heat transfer flow to the TF from the inside face of the receiver, which leads to decrease the heat losses and enhance produced thermal efficiency [35].

So enhancement heat transfer is classified into various methods: active, passive, or merging both previous methods together. In our research, we will focus on the passive enhancement methods that used only one method or that combined two passive techniques together while the enhancement results that reached by the various active methods, like vibration surface, will not be mentioned unless mentioned with a passive category in this manuscript. The passive methods can be summarized by how one can enhance heat transfer with no external force, and these come through: inserting various models (i.e., wire twisted tapes, coils, and porous materials) or modifying the inner and outer surface of the receiver tube, also, inserting metallic and non-metallic nanoparticles in the various base fluids to produce "nanofluid". All categories aimed to improve heat transfer and decrease heat losses by minimizing the thermal boundary condition and increasing the turbulent flow of the fluid flow, which means increasing the mixing rate and reaching high vortex flow, besides, enhancing TFs properties such as thermal conductivity of the resulted fluids [14]. Fig. 4 shows the description flow of the main passive methods, which were used to explain experimental enhancement results that were picked from various scientific articles.

In the following section, the mentioned passive techniques affected in the experimental studies will be explained. The main specifications of different methods and the main results will be summarized and listed.

\subsection{Nanofluid experimental works}

Back in the year 1995, Choi and Eastman are considered as the first researchers who studied the effect of adding

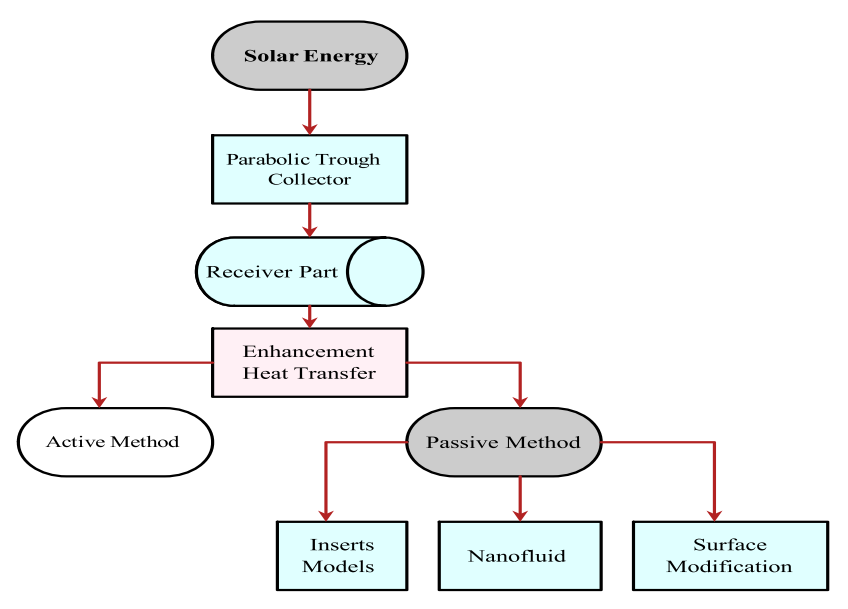

Fig. 4. Passive enhancement methods flow

nanoparticles to the base fluid. In addition, they confirmed the positive effects of enhancing thermo-physical properties, particularly in thermal conductivity [36]. Later, different researchers inserted nanoparticles as a tool to enhance and transfer heat. Their conducted works can be divided into three classes: scientific articles studying different methods that were used in preparation of nanofluid, scientific articles presenting the tested and described nanofluid's thermophysical properties and main correlations that were used to describe these properties, and scientific articles concerned with using nanofluids in different applications such as PTC, flat plate collector, and industrial applications [37-39].

The positive nanofluid effect has emerged in solar applications in recent years, regardless of whether the study was an experimental or numerical work. In this section, experimental scientific works that used nanofluid in PTC will be highlighted from recent years. Table 2 contains a summary of the experimental works that inserted nanofluids as a TF, and the table mainly comprises the base fluid types, 
Table 2. Nanofluid specifications and main findings results

\begin{tabular}{|c|c|c|c|c|c|}
\hline Ref. & Base fluid & Nanoparticle & Concentration & Eff. results max/increase \% & Comments \\
\hline [17] & Water & $\mathrm{Al}_{2} \mathrm{O}_{3}$ & $0.2,0.25,0.3 \% \mathrm{wt}$ & $13 \% \mathrm{Al}_{2} \mathrm{O}_{3}, 11 \% \mathrm{Fe}_{2} \mathrm{O}_{3}$ & Variable flow rate \\
\hline [18] & Water & $\mathrm{Al}_{2} \mathrm{O}_{3}$ & $3,1 \%$ vol & $52.4,73$ & Variable incident angles \\
\hline [19] & Water & $\mathrm{TiO}_{2}$ & $0.05,0.1,0.2,0.5 \% \mathrm{vol}$ & $56.86 / 0.2 \%$ vol & Variable flow rate \\
\hline [20] & Water & $\mathrm{Al}_{2} \mathrm{O}_{3}$ & $0.05,0.1,0.2,0.5 \% \mathrm{vol}$ & 56 & $0.0083,0.016,0.033 \mathrm{~kg} / \mathrm{s}$ \\
\hline [21] & Water & $\mathrm{Fe}_{2} \mathrm{O}_{3}$ & $0.05 \% \mathrm{vol}$ & 16 & Variable MF \\
\hline & & & $0.05 \%$ vol with $\mathrm{MF}$ & 41 & \\
\hline [22] & Mineral oil & MWCNT & $0.2,0.3 \% \mathrm{wt}$ & $\begin{array}{l}4-5 \% / 0.2 \mathrm{wt} \\
5-6 \% / 0.3 \%\end{array}$ & Different receptor tubes \\
\hline [23] & Water & $\mathrm{Al}_{2} \mathrm{O}_{3}$ & $0.1 \% w t$ & $\begin{array}{c}7 \% \\
h=32 \%\end{array}$ & $\begin{array}{l}\text { Constant flow rate } \\
2 \mathrm{~L} / \mathrm{min}\end{array}$ \\
\hline$[24]$ & Water & $\mathrm{CuO}, \mathrm{SiO}_{2}$ & $0.01 \%$ vol & $\begin{array}{l}7.46 \%, 6.68 \% \text { for } 40 \mathrm{~L} / \mathrm{h} \\
8.42 \%, 7.15 \% \text { for } 80 \mathrm{~L} / \mathrm{h}\end{array}$ & $\begin{array}{c}\text { Flow rate } \\
(40,80 \mathrm{~L} / \mathrm{h})\end{array}$ \\
\hline [25] & Water & $\mathrm{Al}_{2} \mathrm{O}_{3}$ & $1,3 \% \mathrm{vol}$ & $0.033 \%$ & Un-evacuated tube \\
\hline [26] & Air & $\mathrm{CuO}$ & - & 65 & Transmitted quartz receiver \\
\hline [27] & $\begin{array}{c}\text { Water } \\
\text { Water + EG }\end{array}$ & $\mathrm{Al}_{2} \mathrm{O}_{3}+\mathrm{CuO}$ & $0.05-0.21 \% \mathrm{vol}$ & 48.03 & $\begin{array}{l}\text { Volume flow }(10-100 \mathrm{~L} / \mathrm{h}) \text { deferent } \\
\text { concentration }\end{array}$ \\
\hline [28] & EG & $\begin{array}{l}\text { MWCNT } \\
\text { Nanosilica }\end{array}$ & $0.1,0.2$, and $0.3 \% \mathrm{vol}$ & $\begin{array}{l}30.4 \% \text { MWCNT } \\
14 \% \text { Nanosilica }\end{array}$ & Direct absorption tube \\
\hline [34] & Water & $\mathrm{Ag}$ & $0-0.1 \%$ vol & $135-205 \%$ & $\begin{array}{c}\text { Constant electricity heat flux and mass } \\
\text { flow rate }\end{array}$ \\
\hline
\end{tabular}

nanoparticle types, mass or volume fractions, and main founding results. Table 3 lists nanofluid preparation methods, specifications of the nanoparticles, and the methods used to get nanofluid thermal properties.

Rehan et al. [17] designed and manufactured a local PTC that has a concentrated ratio equal to 11 . After that, the experimental performance was conducted using different nanoparticles consisting of oxide aluminum and iron based water. A comparison of these nanoparticles with water was made under concentrations $(0.2,0.25$, and $0.3 \%)$ on weight base, and volume flow rate $(1,1.5,2 \mathrm{~L} / \mathrm{min})$. The results of the mentioned cases were performed with variable ambient temperature and wind velocity for the winter of Pakistan. Major results showed enhancements on the thermal efficiency using nanofluids $\mathrm{Al}_{2} \mathrm{O}_{3} / \mathrm{H}_{2} \mathrm{O}$ reaching up to $13 \%$, while it reaches $11 \%$ using $\mathrm{Fe}_{2} \mathrm{O}_{3} / \mathrm{H}_{2} \mathrm{O}$ compared with water at a high flow rate and concentration. De Los Rios et al. [18] investigated the effect of mixing nanoparticle of $\mathrm{Al}_{2} \mathrm{O}_{3}$ in a base fluid of water under the effect of variables incident angle and volume concentration, in order to evaluate the thermal efficiency of the commercial PTC type under those constraints, beside the radiation intensity effect on the university of Tecnológico de Monterrey (Mexico) for the period between April and May 2017. The obtained outcomes

Table 3. Nanofluid preparation and specifications

\begin{tabular}{|c|c|c|c|}
\hline Ref. & Preparation method & $\begin{array}{l}\text { Obtained methods of } \\
\text { thermal properties }\end{array}$ & $\begin{array}{l}\text { Nanoparticle } \\
\text { specification }\end{array}$ \\
\hline [17] & $\begin{array}{l}\text { Add surfactant Triton X-100 two-step } \\
\text { method }\end{array}$ & Correlations & $\begin{array}{c}\mathrm{Al}_{2} \mathrm{O}_{3} 20 \mathrm{~nm} \\
\mathrm{Fe}_{2} \mathrm{O}_{3} 20-40 \mathrm{~nm}\end{array}$ \\
\hline [18] & Two step method & Experimental $k, \rho, \mu$ & $\mathrm{Al}_{2} \mathrm{O}_{3} 10 \mathrm{~nm}$ \\
\hline [19] & $\begin{array}{l}\text { Two step method, Zeta potential } \\
\text { stability }\end{array}$ & Experimental $(k, \mu)$ & $\mathrm{TiO}_{2} 20 \mathrm{~nm}$ \\
\hline [20] & Two step method & Experimental and correlations & $\mathrm{Al}_{2} \mathrm{O}_{3} 40-50 \mathrm{~nm}$ \\
\hline [21] & $\begin{array}{l}\text { Co-precipitation methods. Use sodium } \\
\text { dodecyl }\end{array}$ & Correlations & $\mathrm{Fe}_{2} \mathrm{O}_{3} 10 \mathrm{~nm}$ \\
\hline [22] & Two step method & Not clear & MWCNT $10 \mathrm{~nm}$ \\
\hline [23] & Two step method & Correlations & $40 \mathrm{~nm}$ \\
\hline [24] & Two step method & Correlations & $\begin{array}{l}\mathrm{CuO}(30-40 \mathrm{~nm}) \\
\mathrm{SO}_{2}(20-30 \mathrm{~nm})\end{array}$ \\
\hline [25] & Two step method & Correlations + Experimental results & $\mathrm{Al}_{2} \mathrm{O}_{3} 10 \mathrm{~nm}$ \\
\hline [26] & Injected with flow air & - & $\mathrm{CuO} 7.4 \mathrm{~nm}$ \\
\hline [27] & $\begin{array}{c}\text { Two step method, with Sodium Hexa } \\
\text { surfactant }\end{array}$ & Experimental thermal conductivity & $\begin{array}{l}\mathrm{Al}_{2} \mathrm{O}_{3} 40 \mathrm{~nm} \\
\mathrm{CuO} 100 \mathrm{~nm}\end{array}$ \\
\hline [28] & Two step method & Correlations & $\begin{array}{l}\text { MWCNT } 10 \mathrm{~nm} \\
\text { Nanosilica } 15 \mathrm{~nm}\end{array}$ \\
\hline
\end{tabular}


showed an increase in average thermal efficiency by 52.4 and $40.8 \%$ for nanofluid and water, respectively, under volume concentration equal $1 \%$ and incident angle $10^{\circ}$, while showing an increase in the average thermal efficiency by 43.3 and $33.3 \%$ for nanofluid and water, respectively, under volume concentration equal to $3 \%$ and incident angle $28^{\circ}$. The maximum thermal efficiency observed by various tests regardless of the incident angle reach $63.4 \%$ for water, $73 \%$ for alumina oxide under volume concentration $1 \%$, and $52.4 \%$ for the alumina oxide under volume concentration $3 \%$. Sumbrmani et al. [19] examined the enhancement of thermal efficiency and convective heat transfer using nanofluid of $\mathrm{TiO}_{2}$ with ionized water on the PTC. Whereas measured results were taken for different concentrations (i.e., $0.05,0.1,0.2$, and $0.5 \%$ ), and various flow rates to cover turbulent regimes, which have Reynold numbers between 2,950 and 8,142 . Actually, the results conducted based on the experimental thermo-physical properties showed thermal efficiency enhancement up to $8.66 \%$ and convective heat transfer coefficient up to $22.76 \%$ for $0.2 \%$ volume concentration and $0.0667 \mathrm{~kg} / \mathrm{s}$ mass flow rate. Subramani et al. [20] conducted thermal performance results by inserting $\mathrm{Al}_{2} \mathrm{O}_{3}$ nanoparticles in ionized water in the same PTC and conditions mentioned in the previous study. Obtained results were taken based on varied concentrations and mass flow rates as follow $(0.05,0.1,0.2$, and 0.5$)$ and $(0.0083,0.0167$, $0.033,0.05 \mathrm{~kg} / \mathrm{s})$. The characteristics of the fluid flow were predicted under turbulent conditions. The produced results showed maximum efficiency reach $56 \%$ at concentration $0.5 \%$ and flow rate equal to $0.05 \mathrm{~kg} / \mathrm{s}$, the obtained enhancement on the thermal efficiency of using nanofluid was more than using water in itself by $8.5 \%$. Alsaady et al. [21] performed a study in 2018 on the thermal performance of the direct absorption parabolic trough collector (DAPTC) using magnetic nanofluids and magnetic fields (MFs). This means that two conventional methods comprise active and passive techniques combined in the same experimental work used to present their enhancement effects. Their study was conducted based on a small-scale PTC under volume concentration equal to $0.05 \%$, temperature range $19-40{ }^{\circ} \mathrm{C}$, and mass flow rate $0.025 \mathrm{~kg} / \mathrm{s}$. The obtained results were taken based on different cases. Case I: nanofluid mixing of $\mathrm{Fe}_{2} \mathrm{O}_{3}$ inserting in water. Case II: same nanofluid under variable MF. The results showed maximum thermal efficiency reaching $16 \%$ for the first case while reaching $40 \%$ for the second case under the same concentration. Kasaeain et al. [22] presented through their work a design model of the pilot PTC to improve efficiency and heat transfer. This collector was manufactured with a width equal to $0.7 \mathrm{~m}$ and length equal to $2 \mathrm{~m}$. Through the experiment, the enhancement of the heat and thermal efficiency were presented and tested for four types of the receiver; vacuumed copper, steel tube with black chrome coating, glass enveloped evacuated, and a non-evacuated copper tube with black chrome coating. Finally, they tested nanofluid consisting of multi walled carbon nanotube (MWCNT), inserting it in oil as a base fluid. The effect of nanofluid flow in the pilot PTC using an evacuated receiver tube of copper showed the best enhancement efficiency compared with other types of tubes using the same nanofluid, which was $11 \%$. While the enhancement of thermal efficiency was $5 \%$ for using nanofluid instead of using the oil itself in an evacuated receiver tube of copper. Thermal efficiency and convection heat transfer coefficient were examined by Ghaderian et al. [23] using nanofluid of $\mathrm{Al}_{2} \mathrm{O}_{3} / \mathrm{H}_{2} \mathrm{O}$ flow through the uncovered tube receiver. The experiment was conducted at specific conditions as follows: constant flow rate equal to $2 \mathrm{~L} / \mathrm{min}$ and constant weighted mass concentration equal to $0.1 \%$ at the weather conditions of Nagur, India. The results showed good enhancement in the efficiency and in the heat transfer coefficient increase by 7 and 32\%, respectively. Ajay and Kundan [24] used a small PTC to examine the effect of inserting two types of nanofluid $\left(\mathrm{CuO} / \mathrm{H}_{2} \mathrm{O}\right.$ and $\left.\mathrm{SiO}_{2} / \mathrm{H}_{2} \mathrm{O}\right)$. They also used to enhance thermal efficiency with respect to water itself as a fluid. The experimental and numerical results were derived based on equal volume concentration; i.e. $0.01 \%$ with variable flow rate $(40 \mathrm{~L} / \mathrm{h}$, and $80 \mathrm{~L} / \mathrm{h})$ for each nanofluid. However, the enhancement efficiency at flow rate $40 \mathrm{~L} / \mathrm{h}$ for $\mathrm{CuO} / \mathrm{H}_{2} \mathrm{O}$ and $\mathrm{SiO}_{2} / \mathrm{H}_{2} \mathrm{O}$ was 7.64 and $6.68 \%$, respectively. Also, at flow rate $80 \mathrm{~L} / \mathrm{h}$ it was 8.42 and $7.15 \%$, respectively. Tagle-Salazar et al. [25] thermal performance of commercial Mexican (PTC)-110 was tested experimentally and numerically. However, a minor enhancement of $0.033 \%$ was noticed using nanofluid of $\mathrm{Al}_{2} \mathrm{O}_{3} / \mathrm{H}_{2} \mathrm{O}$ when the volumetric flow rate was $7.53 \mathrm{gpm}$ and volume concentrations were 1 and $3 \%$. Such result comes from using an un-evacuated tube. In addition to this reason, it is worth mentioning that the main aim of this research is to compare the used experimental and numerical methods in finding thermal performance neither of enhancement. Whereas the obtained errors less than $15 \%$ between experimental and numerical thermal efficiency. Potenza et al. [26] investigated the performance of the small transparent-PTC, which used a transparent receiver tube of quartz. The examined transparent receiver, coupled with the nanoparticle of $\mathrm{CuO}$, was injected in air. This transparent-PTC was employed to enhance thermal performance. The measurements were taken using the system circuit consisting of a small transparent-PTC prototype with $4 \mathrm{~m}^{2}$ reflecting area, blower, nanoparticle injector, heat dissipater, and two tanks of water used to control pressure. In addition, the climate parameters of the experimental analysis were held in the weather conditions of Italy. From the results, the maximum outlet temperature was $183{ }^{\circ} \mathrm{C}$ and the mean efficiency reached $65 \%$. The major finding was a deposition of nanoparticles inside the receiver. One of the creative ideas of using different types of nanoparticles mixed and prepared together is called binary or hybrid nanofluid explored by Menbari et al. [27], who prepared and carried out this idea on the (DAPTC) experimentally. The experiment was conducted by inserting binary nanoparticles in the different base fluids such as water or the mixture of water and Ethylene Glycol (EG) at the volume fraction of $50 \%$ for each. This effort was conducted under two aspects: the first one is combining two nanoparticles together, representing high absorption $\mathrm{CuO}$ and high scattering $\mathrm{Al}_{2} \mathrm{O}_{3}$, where the stability, thermal 
conductivity, and sonication time were studied for binary nanofluid of water with EG. The second aspect was used to present the thermal performance of using binary nanofluid under different concentrations and flow rates. In conclusion, the results showed an enhancement of thermal performance when volume fraction and flow rate increase. Whereas maximum efficiency of $48.03 \%$ was observed at a volume fraction of $0.2 \% \mathrm{Al}_{2} \mathrm{O}_{3}$ and $0.008 \%$ of the $\mathrm{CuO}$ when inserted in water as a base fluid at a high mass flow rate.

Kasaeian et al. [28] examined the thermal efficiency of inserting two various types of nanoparticles, namely MWCNT and nanosilica in a base fluid of EG. The experimental test occurred on the same PTC that was used in their previous research [22], but in this research, they used DAPTC consisting of two borosilicate glass layers. The comparison between MWCNT and nanosilica particles reported highly efficient enhancement for that using MWNCT nanofluid at high concentration volume. Reported results show maximum thermal efficiency reaches $72.8 \%$ for MWCNT for concentration $0.3 \%$ under enhancement reach $30.4 \%$ compared with EG, while it reaches 63.6 for nanosilica undergrowth reach $14 \%$ for the same concentration.

Results of the pointed-out articles give a positive improvement on the thermal performance of the PTC using various nanofluids, whereas, this improvement occurs in varying proportions; according to the different aspects the first one is related to the obtained nanofluid, such as base fluid types, size and types of the nanoparticles, preparation technique, and the concentrations. The second one is linked to the conditions of the experiment, like the receiver and parabola parameters, radiation intensity, and the accuracy of the measurement tools. As an example, the maximum thermal efficiency reached under volume concentration equal to $3 \%$ of alumina oxide is less than that for the concentration of $1 \%$. but These results occurred under examining low concentration at low incident angle conditions, so it seems more efficient compared with a high concentration which occurred at high incident angle conditions [18]. Experimentally obtained results prove that the thermal efficiency can be enhanced by increasing flow rate and nanofluid concentration. This was showed clearly in various research [17]. While some research has a negligible enhancement compared with base fluid, where this enhancement did not exceed $0.033 \%$. it is depending on the use of an un-evacuated tube, and the accuracy of measuring test [25]. The achieved overall thermal efficiency using nanofluid flow inside the vacuumed copper tube showed high enhancement results compared with the unvacuumed tubes for the same nanofluid concentration. Which means this tube is more efficient and has a reasonable impact more significant than that of other tubes [22]. A number of studies gained their experimental results under the turbulent flow regime for different concentrations to obtain optimum concentration to reach a desired thermal efficiency [19]. Enhancement results by the coupling effect of using nanofluid with MF reach maximum efficiency of more significance than that occurring by using nanofluid without MF [21]. Increasing thermal efficiency produced by gas-phase nanofluid can be developed by decreasing the deposition by ensuring there is no water content in a gasphase nanofluid. The transparent receiver has low thermal inertia compared with the traditional type; this leads to a sharp drop in the thermal efficiency and the temperature during the cloudy time [26]. To enhance stability and decrease the sedimentation in nanofluid, several studies have used different surfactants to improve the repulsive force between nanoparticles. As mentioned in Menbari research using Sodium-Hexa surfactant enhanced the stability of nanofluid. In addition, it is increasing with increasing surfactant fraction where the optimum value equals 1.25 for binary nanofluid of $\mathrm{CuO}-\mathrm{Al}_{2} \mathrm{O}_{3}$ with water, this because nanoparticles scattering in water is more magnificent than that in the base fluid of EG+ water [27].

According to the aforementioned, all the studies linked the enhancement effect on the PTC using nanofluid with the concentrations as a significant factor to describe the effects of using this method, with the limitations of using high concentrations, whatever volume, or weight connected with the cost (i.e., nanoparticles price, preparation cost) and the enhancement results. So the previous experimental researches occurring under volume and weight concentration ranged from $0.01 \%$ up to $3 \%$, and $0.1 \%$ up to $0.3 \%$, respectively.

\subsection{Inserts model and surface modification experimental works}

Surface geometrical modification and flow inserts are the oldest methods used to enhance heat transfer in different applications. The effect of using these criteria inside the receiver aimed to make the flow more turbulent, whether using various inserts flow model such as twisted tap, porous material or disc, a wire coil, and wavy insert, or using surface modification in the internal or on the surface of the receiver (i.e., internal fins and dimpled). Many of the numerical researches were done in this field of enhancement methods [40], [41]. But unfortunately, there are a few numbers of research done experimentally to obtain a thermal efficiency of the receiver part for PTC. That is why the most significant number of studies focused only on calculated and developed Nusselt number and friction factor correlations to cover various conditions. Mainly in this section, we summarized and presented only the studies specifying the enhancement inside the receiver part for the PTC application using surface receiver modification and insert types. Table 4 describes the major parameters of different methods and main results.

Jamal-Abed et al. [29] investigated the effect of using metal foam of copper inserted in a receiver of PTC. The experimental work was done with a variable volumetric flow rate from 0.5 to $1.5 \mathrm{~L} / \mathrm{min}$, and copper foam specification has porosity and length equal to 0.9 , and $1.25 \mathrm{~m}$, respectively. The results showed a decrease in the overall heat loss coefficient reaching $45 \%$ side by side to the 
Table 4. Inserts types and surface receiver modifications enhancement

\begin{tabular}{|c|c|c|c|}
\hline Reference & Method & Specification & Comment max, Increase \% \\
\hline [29] & Insert foam porosity & $\begin{array}{c}\text { Porosity }=0.9, \text { copper, } \\
\text { Permeability }=1.37 \cdot 10^{-11}\end{array}$ & Enhance thermal efficiency by $3 \%$ \\
\hline [30] & $\begin{array}{l}\text { Twist tapes insert with and } \\
\text { without nails }\end{array}$ & Variable twist ratio $Y=(2,3,5)$ & $\begin{array}{l}\text { Enhance efficiency with nails } \\
\qquad Y(2)=27 \%\end{array}$ \\
\hline [31] & Twist tapes insert with nails & Variable twist ratio $Y=(2,3,5)$ & $\begin{array}{c}\text { Maximum peak efficiency } \\
Y(4.787)=64.2\end{array}$ \\
\hline [32] & $\begin{array}{l}\text { Internally Multiple fins } \\
\text { un-evacuated tube }\end{array}$ & $\begin{array}{c}\text { Fin thickness } 1.5 \mathrm{~mm} \text {, fin } \\
\text { distance } 1.5 \mathrm{~mm}\end{array}$ & $\begin{array}{l}\text { The air was the base fluid, Maximum } \\
\text { efficiency } 40.6 \text { for } 0.00434 \mathrm{~m}^{3} / \mathrm{s}\end{array}$ \\
\hline [33] & Insert porous disc & Various shape & $\begin{array}{c}\text { Maximum } 69.26 \text { for alternative porous } \\
\text { disc type }\end{array}$ \\
\hline [34] & Twisted tapes inserts and nanofluid & Various helix angle and tapes ratio & $135-205 \%$ \\
\hline
\end{tabular}

enhancement of the thermal efficiency found approximately 3\%. Jafar and Sivaraman [30] examined PTC under the outdoor condition of Annamalai University, India. This experiment aimed to calculate thermal improvement efficiency, fraction factor effects, and Nusselt number that was performed by using twisted tap inserts and twisted tap with nails. The thermal enhancement results were compared with base fluid itself. The results of using twisted tap varying under ratio $Y=(2,3,5)$ showed enhancement in thermal performance reach $27 \%$ at a twisted ratio equal to 2 compared with other ratios and base fluids. Bhakta et al. [31] examined the effect of using nails twisted tapes insert in the receiver tube of PTC. This configuration was studied under different ratios compared with the previous research. The experimental was carried out from April to June 2017 due to India's weather, under the examined ratio of the nails tapes having 4.787, 6.914, 9.042. The results of the useful heat, thermal performance, and thermal efficiency were presented. Where the maximum instantaneous efficiency was reached $64.28 \%$ under enhancement value equal to $15.15 \%$ compared with plain absorber receiver for small twist tapes ratio at the peak time of the day. Nemś and Kasperski [32] designed a prototype PTC and examined its thermal efficiency of the airflow inside the receiver having internally multiple fins. Thermal efficiency results were obtained under climate change of Poland for summer and variable airflow of the fluid. The results presented maximum efficiency equal to $40.6 \%$ for air flux equal to $0.00434 \mathrm{~m}^{3} / \mathrm{s}$. Reddy et al. [33] reported the effect of using different porous discs inside the receiver part of the PTC. The experimental works compared thermal efficiency enhancement resulted by various configurations porous discs (i.e., bottom, U-shaped, inclined, U-shaped bottom, finally alternative which have a sequence of up and down porous disc). Actually, the results showed that the alternative disc has the best configurations according to the maximum efficiency reached, which is equal to $69.42 \%$.

The main results of using inserts type flow and surface receiver modification and its descriptions are summarized in Table 4, where minimum enhancement referred to used unevacuated tube.

\subsection{Passive methods combined (nanofluid and inserts types or surface receiver modification augmentation)}

In this section of our review, the experimental researches that combined two passive methods to enhance thermal efficiency in the receiver part of the PTC are discussed. Actually, most of the research in this field concentrated in obtaining the thermal performance convective coefficient, Nusselt number, friction factor inside the various tubes under laminar, and turbulent flow aloof of in studying their effects in a receiver part of PTC. So various experimental works in this field aimed to obtain the correlations that cover convective coefficient and Nusselt number under limited constraints, that can be used later to estimate thermal efficiency produced by PTC under the same constraints. This means this aspect needs more intensive work, especially in the experimental studies for PTC in the coming years according to the limited research in this field, coinciding with predicted improvements that can occur.

Waghole et al. [34] examined the combined effect of inserting silver nanoparticles in water (Passive 1) with twisted tap inserts (Passive 2) in the heat transfer performance of the receiver tube of PTC experimentally. The test was done under variable Reynold's number 500-6,000, volume concentration $0-0.1 \%$, and various tapes ratios 0.577 , 1.0, and 1.732. The results showed enhancement compared with the plane tube as follows 1.25-2.1, 1.0-1.75, 135-205\% for Nusselt number, friction factor, and efficiency, respectively. Finally, they developed correlations that can be used to estimate Nusselt number and friction factor for water with twisted tapes inserts, and for silver nanofluid with twisted tap inserts for the mentioned constraints.

\section{CONCLUSIONS}

The experimental researches that are related to enhancing thermal performance in the receiver part of PTC using whatever nanofluid, receiver surface modification, and inserts types are not many. This study tried to give spotlights on the experimental works in recent years between the 
period of 2014-2019, related to the thermal enhancement performance in the absorber using nanofluid, surface modification, and different inserts types. This period was chosen due to the increase in the interest of using various methods to enhance the thermal efficiency of the solar PTC application. The following points summarize the main findings:

- Using nanofluid as a promising method proof of its effects used to enhance the thermal performance of the PTC was effective and showed a variable enhancement ratio. The results of most studies showed that using this method will enhance the thermal performance of the PTC.

- Different types of nanoparticles were used through experimental researches, namely $\mathrm{Al}_{2} \mathrm{O}_{3}, \mathrm{Fe}_{2} \mathrm{O}_{3}, \mathrm{TiO}_{2}$, MWCNT, $\mathrm{CuO}, \mathrm{SiO}_{2}, \mathrm{Ag}$, Nanosilica, while other available nanoparticles such as $\mathrm{Fe}, \mathrm{Cu}, \mathrm{Zn}, \mathrm{CuO}_{2}, \mathrm{CNT}$, SWNT have not been examined experimentally until now.

- Inserting nanoparticle in various base fluids like water, EG, and oil, showed a high interest in using water as a base fluid more than other base fluids, because it is available and inexpensive. Moreover, most of the mentioned experimental works were designed to cover low and medium temperatures.

- Nanofluid flow was examined in various types of receiver tubes like the un-evacuated receiver, the evacuated receiver covered by high absorption material and the direct absorption tube (glass-glass), where the reported results showed that the minimum enhancement was obtained using the un-evacuated tube [25]. Moreover, using direct absorption receiver requires more interest in the optical and absorptivity properties of the chosen nanoparticle to enhance their effectiveness as much as possible.

- Stability of the producing nanofluid is one of the most important factors that takes a high interest. This factor was studied from several aspects like sonication time, surfactant, properties of various nanoparticles and base fluids.

- From the literature review, it is obvious that the experimental works have a few number of articles focused on the enhancement of thermal performance using combined nanoparticles together (hybrid) [27], gathered nanofluid with active methods [21], and combined nanofluid with other passive techniques like inserts and surface receiver modification [34]. Thus, more efforts are needed in the experimental works in these aspects.

\section{RECOMMENDATIONS}

Regarding what has been discussed in this paper, several recommendations were taken based on the literature and experience, as follow:

- Experimental works of enhancing thermal performance on the receiver part of the PTC need intensive work during the coming years.

- The cost of using nanofluid categories to enhance the thermal performance of the PTC need intensive work

especially on a large scale to give perception about the applicability of using this category in a wide range.

- Different types of inserts and surface receiver modifications are not tested experimentally on the PTC. They are recommended to be used (i.e., baffle inserts, and treated surface).

- The effect of inserting nanoparticles in different oil types (i.e., Therminol, Syltherm 800) needs more research particularly in testing PTC at high-level temperature. Because these liquids are able to withstand high temperatures with no phase change.

- The combination of nanofluids with different categories of enhancement (i.e., surface receiver modification, and inserts effects) needs more significant attention in future experimental works.

- Preparing mono and hybrid nanofluids that have high stability and examining their effect in the thermal performance of PTC needs more efforts in the future experimental works.

- Mono and hybrid nanofluid with surface receiver modification or with inserts types is a creative method that has a significant and efficient impact as proved in reference [34]. So, it is recommended to go toward this side.

- To decrease the cost that is required with commercial oil and to show the thermal results predicted from available oil. It is recommended to use available natural oil as a base fluid and test them experimentally.

- Most of the experimental research studies focused on the use of certain types of the nanoparticles rather than other, and the effects of some of the nanoparticles are unknown until now because they have not been tested or studied. It is recommended to continue studying different types of nanoparticles and present the effect of using different shapes and diameters on the thermal performance of the PTC.

\section{NOMENCLATURE}

A

fluid

$C_{p}$

in

D

loss

$G_{b}$

$o$

$k$

$r$

$L$

$s$

$\dot{m}$

th

Q

u

T

$U_{l}$

\author{
Area $\left[\mathrm{m}^{2}\right]$ \\ fluid \\ specific heat capacity $[\mathrm{J} / \mathrm{kg} \mathrm{K}]$ \\ inlet, inner \\ Diameter [mm] \\ losses \\ direct beam irradiance intensity $\left[\mathrm{W} / \mathrm{m}^{2}\right]$ \\ out \\ thermal conductivity $[\mathrm{W} / \mathrm{m} \mathrm{K}]$ \\ receiver \\ length $[\mathrm{m}]$ \\ sensible \\ mass flow rate $[\mathrm{kg} / \mathrm{s}]$ \\ thermal \\ heat flux [W] \\ useful \\ temperature [K]Abbreviations \\ thermal loss coefficient $\left[\mathrm{W} / \mathrm{m}^{2} \mathrm{~K}\right]$
}




$\begin{array}{ll}\text { CSP } & \text { concentrated solar power } \\ W & \text { width [m] } \\ \text { DAPTC } & \text { direct absorption parabolic trough collector } \\ \eta & \text { efficiency [-] } \\ \text { EG } & \text { Ethylene GlycolSubscripts } \\ \text { MF } & \text { magnetic field } \\ \text { ap } & \text { aperture } \\ \text { MWCNT } & \text { multi walled carbon nanotube } \\ \text { amb } & \text { ambient } \\ \text { PTC } & \text { parabolic trough collector } \\ b & \text { beam } \\ \text { TF } & \text { thermal fluid }\end{array}$

\section{REFERENCES}

[1] A. Kassem, K. Al-Haddad, D. Komljenovic, and A. Schiffauerova, "A value tree for identification of evaluation criteria for solar thermal power technologies in developing countries," J. Sustain. Energy Technol. Assess., vol. 16, pp. 18-32, 2016.

[2] S. Adibhatla and S. Kaushik, "Energy, exergy, economic and environmental (4E) analyses of a conceptual solar aided coal fired 500 MWe thermal power plant with thermal energy storage option," J. Sustain. Energy Technol. Assess., vol. 21, pp. 89-99, 2017.

[3] N. Panwar, S. Kaushik, and S. Kothari, "Role of renewable energy sources in environmental protection: A review," J. Renew. Sustain. Energy Rev., vol. 15, no. 3, pp. 1513-24, 2011.

[4] A. Kumar, K. Kumar, N. Kaushik, S. Sharma, and S. Mishra, "Renewable energy in India: Current status and future potentials," J. Renew. Sustain. Energy Rev., vol. 14, no. 8, pp. 2434-42, 2010.

[5] T. Tsoutsos, N. Frantzeskaki, and V. Gekas, "Environmental impacts from the solar energy technologies," J. Energy Policy, vol. 33, no. 3, pp. 289-96, 2005.

[6] S. A. Kalogirou, "Solar thermal collectors and applications," $J$. Progr. Energy Combust. Sci., vol. 30, no. 3, pp. 231-95, 2004.

[7] W. Fuqiang, C. Ziming, T. Jianyu, Y. Yuan, S. Yong, and L. Linhua, "Progress in concentrated solar power technology with parabolic trough collector system: A comprehensive review," $J$. Renew. Sustain. Energy Rev., vol. 79, pp. 1314-28, 2017.

[8] G. Espinosa-Rueda, J. L. N. Hermoso, N. Martínez-Sanz, and M. Gallas-Torreira, "Vacuum evaluation of parabolic trough receiver tubes in a $50 \mathrm{MW}$ concentrated solar power plant," J. Solar Energy, vol. 139, pp. 36-46, 2016.

[9] J. Pytilinski, "Solar energy installations for pumping irrigation water," J. Solar Energy, vol. 21, no. 4, pp. 255-62, 1978.

[10] C. Turchi, M. Mehos, C. K. Ho, and G. J. Kolb, Current and Future Costs for Parabolic Trough and Power Tower Systems in the US Market, Golden, CO, United States, National Renewable Energy Lab. (NREL), 2010.

[11] S. Pavlovic, E. Bellos, V. Stefanovic, and C. Tzivanidis, "Optimum geometry of parabolic trough collectors with optical and thermal criteria," J. Int. Rev. Appl. Sci. Eng., vol. 8, no. 1, pp. 45-50, 2017.

[12] A. Hafez, A. Attia, H. Eltwab, A. ElKousy, A. Afifi, A. AbdElhamid, et al. "Design analysis of solar parabolic trough thermal collectors," J. Renew. Sustain. Energy Rev., vol. 82, pp. 1215-60, 2018.

[13] A. J. Abdulhamed, N. M. Adam, M. Z. A. Ab-Kadir, and A. A. Hairuddin, "Review of solar parabolic-trough collector geometrical and thermal analyses, performance, and applications," J. Renew. Sustain. Energy Rev., vol. 91, pp. 822-31, 2018.

[14] S. Akbarzadeh and M. S. Valipour, "Heat transfer enhancement in parabolic trough collectors: A comprehensive review," J. Renew. Sustain. Energy Rev., vol. 92, pp. 198-218, 2018.

[15] K. Khanafer and K. Vafai, "A review on the applications of nanofluids in solar energy field," J. Renew. Energy, vol. 123, pp. 398-406, 2018.

[16] J. A. Duffie and W. A. Beckman, Solar Engineering of Thermal Processes, John Wiley \& Sons, 2013.

[17] M. A. Rehan, M. Ali, N. A. Sheikh, M. S. Khalil, G. Q. Chaudhary, T. ur Rashid, et al. "Experimental performance analysis of low concentration ratio solar parabolic trough collectors with nanofluids in winter conditions," J. Renew. Energy, vol. 118, pp. 742-51, 2018.

[18] M. S. B. De los Rios, C. I. Rivera-Solorio, and A. J. García-Cuéllar, "Thermal performance of a parabolic trough linear collector using Al2O3/H2O nanofluids," Renew. Energy, vol. 122, pp. 665-73, 2018.

[19] J. Subramani, P. Nagarajan, O. Mahian, and R. Sathyamurthy, "Efficiency and heat transfer improvements in a parabolic trough solar collector using $\mathrm{TiO}_{2}$ nanofluids under turbulent flow regime," Renew. Energy, vol. 119, pp. 19-31, 2018.

[20] J. Subramani, P. Nagarajan, S. Wongwises, S. El-Agouz, and R. Sathyamurthy, "Experimental study on the thermal performance and heat transfer characteristics of solar parabolic trough collector using $\mathrm{Al}_{2} \mathrm{O}_{3}$ nanofluids," Environ. Progr. Sustain. Energy, vol. 37, no. 3, pp. 1149-59, 2018.

[21] M. Alsaady, R. Fu, Y. Yan, Z. Liu, S. Wu, and R. Boukhanouf, "An experimental investigation on the effect of ferrofluids on the efficiency of novel parabolic trough solar collector under laminar flow conditions," J. Heat Transf. Eng., vol. 40, no. 9-10, pp. 753-61, 2019.

[22] A. Kasaeian, S. Daviran, R. D. Azarian, and A. Rashidi, "Performance evaluation and nanofluid using capability study of a solar parabolic trough collector," J. Energy Convers. Manag., vol. 89, pp. 368-75, 2015.

[23] J. Ghaderian and N. A. C. Sidik, "An experimental investigation on the effect of $\mathrm{Al} 2 \mathrm{O} 3 /$ distilled water nanofluid on the energy efficiency of evacuated tube solar collector," Int. J. Heat Mass Transfer., vol. 108, pp. 972-87, 2017.

[24] K. Ajay and L. Kundan, "Combined experimental and CFD investigation of the parabolic shaped solar collector utilizing nanofluid $\left(\mathrm{CuO}-\mathrm{H}_{2} \mathrm{O}\right.$ and $\left.\mathrm{SiO}_{2}-\mathrm{H}_{2} \mathrm{O}\right)$ as a working fluid", J. Eng. pp. 1-11, 2016.

[25] P. D. Tagle-Salazar, K. Nigam, and C. I. Rivera-Solorio, "Heat transfer model for thermal performance analysis of parabolic trough solar collectors using nanofluids," J. Renew. Energy, vol. 125, pp. 334-43, 2018.

[26] M. Potenza, M. Milanese, G. Colangelo, and A. de Risi, "Experimental investigation of transparent parabolic trough collector based on gas-phase nanofluid," J. Appl. Energy, vol. 203, pp. 560-70, 2017.

[27] A. Menbari, A. A. Alemrajabi, and A. Rezaei, "Experimental investigation of thermal performance for direct absorption solar parabolic trough collector (DASPTC) based on binary nanofluids," J. Exp. Thermal Fluid Sci., vol. 80, pp. 218-27, 2017.

[28] A Kasaeian, R Daneshazarian, R Rezaei, F Pourfayaz, and G. Kasaeian, "Experimental investigation on the thermal behavior of 
nanofluid direct absorption in a trough collector," J. Clean. Produc., vol. 158, pp. 276-84, 2017.

[29] M. T. Jamal-Abad, S. Saedodin, and M. Aminy, "Experimental investigation on a solar parabolic trough collector for absorber tube filled with porous media," Renew. Energy, vol. 107, pp. 156-63, 2017.

[30] K. S. Jafar and B. Sivaraman, "Performance characteristics of parabolic solar collector water heater system fitted with nail twisted tapes absorber," J. Eng. Sci. Technol., vol. 12, no. 3, pp. 608-21, 2017.

[31] A. K. Bhakta, N. K. Panday and S. N. Singh, "Performance study of a cylindrical parabolic concentrating solar water heater with nail type twisted tape inserts in the copper absorber tube," Energies, vol. 11, no. 1, p. 204, 2018.

[32] M. Nemś and J. Kasperski, "Experimental investigation of concentrated solar air-heater with internal multiple-fin array," Renew. Energy, vol. 97, pp. 722-30, 2016.

[33] K. Reddy, K. R. Kumar, and C. Ajay, "Experimental investigation of porous disc enhanced receiver for solar parabolic trough collector," Renew. Energy, vol. 77, pp. 308-19, 2015.

[34] D. R. Waghole, R. Warkhedkar, and R. Shrivastva, "Experimental investigations on heat transfer and friction factor of silver nanofluid in absorber/receiver of parabolic trough collector with twisted tape inserts," J. Energy Proc., vol. 45, pp. 558-67, 2014.

[35] R. V. Padilla, G. Demirkaya, D. Y. Goswami, E. Stefanakos, and M. M. Rahman, "Heat transfer analysis of parabolic trough solar receiver," Appl. Energy, vol. 88, no. 12, pp. 5097-110, 2011.

[36] S. Chol and J. Estman, "Enhancing thermal conductivity of fluids with nanoparticles," ASME-Publications-Fed, vol. 231, pp. 99-106, 1995.

[37] D. K. Devendiran and V. A. Amirtham, "A review on preparation, characterization, properties and applications of nanofluids," Renew. Sustain. Energy Rev., vol. 60, pp. 21-40, 2016.

[38] D. D. Kumar and A. V. Arasu, "A comprehensive review of preparation, characterization, properties and stability of hybrid nanofluids," Renew. Sustain. Energy. Rev. vol. 81, pp. 1669-89, 2018.

[39] A. Kasaeian, A. T. Eshghi, and M. Sameti, "A review on the applications of nanofluids in solar energy systems," J. Renew. Sustain. Energy. Rev., vol. 43, pp. 584-98, 2015.

[40] A. Mwesigye, T. Bello-Ochende, and J. P. Meyer, "Heat transfer and thermodynamic performance of a parabolic trough receiver with centrally placed perforated plate inserts," Appl. Energy, vol. 136, pp. 989-1003, 2014.

[41] K. Reddy and G. Satyanarayana, "Numerical study of porous finned receiver for solar parabolic trough concentrator," Eng. Appl. Comput. Fluid Mech., vol. 2, no. 2, pp. 172-84, 2008. 